\title{
Magnitude of metabolic syndrome among middle aged adulthood urban residents in West Ethiopia
}

\author{
Alemu Adeba ${ }^{*}$, Dessalegn Tamiru,Tefera Belachew \\ Department of Nutrition and Dietetics, Faculty of Public Health, Wollega University, Ethiopia \\ Department of Nutrition and Dietetics, Faculty of Public Health, Jimma University, Ethiopia \\ E-mail address: \\ alemuadeba2017@gmail.com \\ dessalegn97@gmail.com \\ teferabelachew2@gmail.com
}




\begin{abstract}
Background: Nowadays, most of the people die due to metabolic impairment. Metabolic syndrome is a major health threat facing all people worldwide. However it is a silent killer; community based screening was not practiced, especially in west Ethiopia. Thus, this study aimed to assess magnitude of metabolic syndrome among middle aged urban residents.
\end{abstract}

Methods: A community based cross sectional study design was applied on 266 healthy adults in March 2019. Data was collected with questionnaires, anthropometric measures and biomarkers. By using SPSS version 24, magnitude of metabolic was indentified; statistical associated significant of variables were considered at $\mathrm{p} \leq 0.05$ on multivariable logistic regression analysis.

Results: Using the new clinical definition of the metabolic syndrome given by International Diabetes Federation the prevalence of metabolic syndrome was $12.6 \%$ while $15.4 \%$ as of Ethiopian cut off point. The prevalence of central obesity was $47.1 \%$ as of International Diabetes Federation, 2018 while $58.6 \%$ as of Ethiopian. By separate components the most frequent metabolic syndrome parameters; blood pressure, hyperglycemia and low density lipoprotein were $18.4 \%, 24.4 \%, 20.4 \%$ and $19.5 \%$ respectively. Majority $(91.7 \%)$ of participants had unhealthy lifestyles. Findings of binary analysis showed those who had serum triglycerides level $\geq 150 \mathrm{mg} / \mathrm{dL}$ was found to increased risks of metabolic syndrome by more than one hundred thirteen times $(\mathrm{OR}=113.18 \mathrm{CI}=36.05-355.29)$. On multivariate analysis those who had body mass index $\geq 25 \mathrm{Kg} / \mathrm{m}^{2}$ was found to increased risks of metabolic syndrome by more than twenty one times (AOR: 25.67; 95\% CI 7.18, 94.59; $\mathrm{p}<0.001$ ), more than twelve times those found with central obesity (AOR:12.74; p, 0.015), more than nine times for systolic blood pressure $\geq 130 \mathrm{mmHg}$ (AOR: 9.30; P, 0.039), and fourfold greater for $\mathrm{FBS} \geq 100 \mathrm{mg} / \mathrm{dl}$ (AOR: 4.42; $\mathrm{P}<0.001)$.

Conclusion: This study reveals magnitude of metabolic syndrome was high among middle aged urban residents of west Ethiopia. Therefore, educating community on metabolic syndrome prevention was significant to mitigate complication from degenerative diseases.

Key words: Metabolic syndrome, lifestyles, magnitude, middle aged, west Ethiopia 


\section{INTRODUCTION}

The global prevalence of NCDs is increasing rapidly, including low and middle income countries and in 2012 almost 75\% of NCD-related deaths where took place [1]. In developing countries, over-nutrition is second 'silent emergency' due to rapid urbanization and shifting of diet [2] and $79 \%$ of deaths attributable to chronic diseases are occurring mostly during middle aged[3].

In $2000 \mathrm{WHO}$ reported that about 800,000 cases were recorded in Ethiopia, and this number projected to rise to 1.8 million by 2030. Also WHO reported in 2013 showed about 1.9 million diabetic patients seen in Ethiopia [4, 5]. Findings from Tikur Anbessa Specialized Hospital also reveals $9.9 \%$ of undiagnosed employees in that hospital were at high risk for developing T2DM and about $13.9 \%$ of the female had gestational diabetic mellitus[6].

Risks of NCDs are increasing as a result of unhealthy lifestyles, such as tobacco, unhealthy diet, risky alcohol drinking and physical inactivity [7]. Metabolic syndrome is of the result of interconnected physiological, biochemical, clinical, and metabolic factors. It also defined as having abdominal obesity plus any two or more of the following risk factors: elevated blood pressure, reduced high-density lipoprotein cholesterol (HDL-C), elevated triglyceride levels and raised fasting plasma glucose [8-10].

Unhealthy lifestyles are the most common modifiable risk factors of metabolic syndrome. The impact of unhealthy lifestyles not only undermines quality of life and productivity, but also contributes death and economic losses. Morbidity costs represent lost income from reduced productivity, restricted physical activity, and absenteeism and bed days. Mortality costs encompass lost future income due to premature death [11]. According to Ethiopian Public Health Institute report in 2016, the cumulative economic losses due to NCD burden in low \& middle income countries between 2011 and 2025 have been estimated US\$7 trillion. Population norms for HRQoL are an essential ingredient in health economics and in the evaluation of population health [12].

Degenerative diseases can be delayed, prevented, or managed through healthy behaviors [13], yet lifestyles-related health risk factors is still lack focus. In 2013, the American Medical Association classified obesity as a disease. It is most commonly caused by a combination of unhealthy diet, physical in activities and genetic susceptibility. Dieting and exercising is medicine for obesity and reducing disability and death from chronic diseases [14, 15]. Promotion of healthy diets and of physical activity should be a core competence of primary care providers, 
who play an important role in providing individual services to tackle the burden of NCDs [16]. Nutrition transition exacerbated by decreased physical activity, stressful lifestyle, and risky alcohol drinking and tobacco use $[17,18]$.

The prevalence of metabolic syndrome increases could be due to a rapid nutrition transition such as high-calorie intake, high fat consumption, and low consumption of dietary fiber foods, as well as behavioral factors like sedentary lifestyles, increase in tobacco use, and excessive alcohol consumption [19]. Also migration from rural to urban [20] and nature of blackness in habitant mostly risk for prevalence of metabolic syndrome [21].

Study conducted in Addis Ababa revealed, the prevalence of metabolic syndrome was $14.0 \%$ in men and $24.0 \%$ in women [22]. Similarly; according to IDF definition in the study population the overall prevalence rate of Metabolic Syndrome (Met S-IDF) in Jimma Town was estimated to be $(16.7 \%)$ [23].

Even though metabolic syndrome is prevalent in urban areas particularly workforces and women, in Ethiopia the effect not yet registered nationwide. Also Ethiopia had no optimal cut-off points for defining metabolic syndrome and risk components of adults, rather than using cot-off points from Caucasian population [25].Screening for metabolic disorders among healthy individuals is ignored as the literatures showed [26]; evidence also suggests that an abnormal metabolic profile, rather than high BMI, is associated with higher risk of diabetes and cardiovascular diseases [27].

In line with the concept, because of chronic degenerative diseases most of young age adults are dying due to metabolic age than chronological ageing. Unless risk factors of metabolic syndrome are prevented earlier, the consequences range from serious chronic conditions to premature death. Therefore, this study aimed to assess prevalence of metabolic syndrome and its associated factors among middle aged urban residents in West Ethiopia.

\section{METHODS}

\section{Study design and setting}

A community based cross-sectional study design was adopted in accordance with approaches of WHO to conduct the research on middle age urban residents in West Ethiopia. Because of hub center for western towns (Assosa, Ambo, Bure-Bahirdar, Metu and Jimma) we selected Nekemte. It is $328 \mathrm{~km}$ far from Addis Ababa (Finfinne) and has six kebeles. Its city projection in 2017 is estimated to be 117,819 and out of this adults $51 \%(117,819=60,088)$ [27]. This Town has one specialized Hospital, one referral Hospital, and three Health centers. Community based 
education on healthy lifestyle adoption, prevention of risk factors of metabolic syndrome and improvement of quality of life was being given from 1February- 1August 2019, so these results serve as baseline and the data was collected in February 2019.

\section{Source and study population}

All middle aged adults (41-64years) among Nekemte residents during the study time were the source of population. While all middle aged (41-64 years) adults in the selected communes and registered as a resident and had lived in community for greater than six months were be included in study population.

\section{Inclusion and exclusion criteria}

Participants who lived at least six months and aged 41 to 64 years who were eligible to participate in the study However, those on medication and have known cardiovascular disease; attended behavioral change communication program; pregnant \& lactating; bariatric surgery; us anti-psychotics and physically disables were excluded

\section{Sample and Sampling techniques}

Two hundred sixty six participants calculated using a single finite population proportion formula by using Epi Info ${ }^{\mathrm{TM}} 7$ by considering with the following assumptions: margin of error of 5\%, confidence level of $95 \%, 10 \%$ non-response rate and central obesity $(19.6 \%)$ the most common prevalent metabolic syndrome component Ethiopian adults [40].

From six kebeles (small administrative unit), two kebeles which were not adjacent but homogeneous in terms of socioeconomically and geographically were selected. Since data was used as baseline for an intervention, one kebele was randomly selected and the other was purposively allocated with buffering zone through natural geography to avoid data contamination.

\section{Data collection}

Data were gathered using structured questionnaires through interview of adults in the local language that translated from English version by trained research assistants. Self administered questionnaires and anthropometric and biochemical measurements were used to collect data. Anthropometric assessment of adults carried out using standardized techniques. Weight and height measurements will be taken using calibrated equipment (Taylor Lithium Electronic Scale for weight and a portable stadiometer/sac-Germany) with light clothes and no shoes. 
For laboratory analysis, $5 \mathrm{ml}$ of venous blood samples from the ante-capital vein was taken after. The study participants were advised to take an overnight fasting of 10-12 hours before collecting the blood samples for the determination of FBG and lipid profiles. Fasting blood (plasma) glucose, serum total cholesterol, HDL-C and triglycerides were determined by Auto analyzer (Human Star Model 80) method by using specific reagents (Human). LDL-C was calculated using the Freidwald formula. VLDL $=$ Triglycerides $\div 5 ; \mathrm{LDL}=$ Total cholesterol $-(\mathrm{HDL}+$ VLDL) [28].

The anthropometric assessment was done according to the standardized procedures stipulated by the Food and Nutrition Technical Assistance (FANTA) Anthropometric Indicators Measurement Guide by seca Germany [29].

\section{Operational definitions}

Metabolic syndrome was defined as presence of central obesity as defined using the new clinical definition of the metabolic syndrome given by International Diabetes Federation $(>90 \mathrm{~cm} / 80 \mathrm{~cm}$ for male/female[48] and (waist circumference $83.7 \mathrm{~cm}$ for males and $78.0 \mathrm{~cm}$ for females, BMI $>22.2 \mathrm{in}$ men and $24.5 \mathrm{~kg} / \mathrm{cm} 2$ in women since Ethiopian have10\% less slim[25] ,; Plus any two of the following factors: raised Triglycerides level: $\geq 150 \mathrm{mg} / \mathrm{dl}(1.7 \mathrm{~m} \mathrm{~mol} / \mathrm{L})$, reduced HDL-cholesterol: $<40 \mathrm{mg} / \mathrm{dl}(1.03 \mathrm{~m} \mathrm{~mol} / \mathrm{L})$ in males and $<50 \mathrm{mg} / \mathrm{dl}(1.29 \mathrm{mmol} / \mathrm{L})$ in females, raised Blood Pressure: systolic $\mathrm{BP} \geq 130$ or diastolic $\mathrm{BP} \geq 85 \mathrm{~mm} \mathrm{Hg}$, and raised Fasting Plasma Glucose $(\mathrm{FPG}) \geq 100 \mathrm{mg} / \mathrm{dl}(5.6 \mathrm{~m} \mathrm{~mol} / \mathrm{L})$. In addition $\mathrm{BMI} \geq 25 \mathrm{~kg} / \mathrm{m}^{2}$ was overweight $[16,48]$.

Diet diversity was constructed according to FAO 2013, by counting the intake of the food groups over a period of one week based on the sum of food groups consumed over the reference period. For instance, an adult who consumed one item from each of the food groups at least once during the week would have the maximum DDS.

\section{Data Analysis}

Data analyses were done using SPSS for windows version 24(Chicago, Illinois) after checking for missing values and outliers. Descriptive analysis was carried out using risk score as dependent variable, with age, gender, smoking, physical activity, BMI, WC, ethnicity, educational status, religion, income, fruits and vegetables eating habit, previously measured history of blood glucose \& pressure, presence of metabolic syndrome. 
Regression analysis was used to identify the factors associated with metabolic syndrome. Binary logistic regression was used to determine the association between lifestyles with modifiable risk factors of metabolic syndrome \& health related quality of life. Variables with P-value $\leq 0.25$ in binary analysis was selected as candidate variables multivariable logistic regression model to identify association of independently factors. Odds ratio together with their corresponding 95\% CI was computed. Multi-co linearity among independent variables was assessed using the standard errors. The standard errors for regression coefficients $<2.0$, as a familiar cutoff value, showed that there was no multicollinearity among independent variables. Normality was checked for continuous variables. A P-value $<0.05$ was considered as statistically significant.

\section{RESULTS}

\section{Socio demographic characteristics of participants}

From two hundred sixty six undiagnosed populations $62.8 \%$ were females. On average the age of study participants were 52.5 years and largest population (89.5\%) was Oromo followed by Amhara (6\%). Likewise, $41.4 \%$ of the respondents were live in lowest wealth quintiles. Similarly, almost all (92.5\%) of respondents did not have urban farming/home gardening and $54.9 \%$ of them living below poverty threshold (Table 1 ).

Table1 Socio-demographic characteristics of middle aged urban residents, west Ethioipa,2019

\begin{tabular}{llrr}
\hline Variables & Categories & Frequency (n) & Percent (\%) \\
\hline Gender & Female & 167 & 62.8 \\
Age in years & Male & 99 & 37.2 \\
& $41-48$ & 145 & 54.5 \\
Educational status & $49-56$ & 77 & 28.9 \\
& $57-64$ & 44 & 16.5 \\
& Illiterate & 86 & 32.3 \\
& some school & 119 & 44.7 \\
Marital status & Diploma/certificate & 33 & 12.4 \\
& Degree and above & 28 & 10.5 \\
& Single & 13 & 4.9 \\
& Married & 178 & 66.9 \\
& Widowed & 56 & 21.1 \\
Religious & Divorced & 19 & 7.1 \\
& Protestant & 160 & 63.9 \\
& Orthodox & 88 & 33.1 \\
& Muslim & 6 & 2.3 \\
& Wakefata & 11 & 0.4 \\
& Others & 1 & 0.4
\end{tabular}




\begin{tabular}{llrr} 
Ethnicity & Oromo & 238 & 89.5 \\
& Amhara & 16 & 6.0 \\
& Tigre & 6 & 2.3 \\
& Others & 6 & 2.3 \\
Occupation status & Job less & 135 & 50.8 \\
& light work & 30 & 11.3 \\
& long hour sitting work & 61 & 22.9 \\
& Long stand work >4hrs & 40 & 15.0 \\
Estimated average & -37.5 USD & 146 & 54.9 \\
monthly income & $37.5-75$ USD & 74 & 27.8 \\
& $75-100$ USD & 9 & 3.4 \\
\multirow{5}{*}{ Urban farming } & Yes & 37 & 13.9 \\
Wealth quintiles & No & 20 & 7.5 \\
& Lowest/the poorest & 246 & 92.5 \\
& Second quintiles & 110 & 41.4 \\
& Middle quintiles & 80 & 30.1 \\
& Fourth quintiles/richest & 68 & 25.6 \\
& & 8 & 3.0 \\
\hline
\end{tabular}

\section{Common modifiable risk factors of metabolic syndrome}

Out of the 266 participants, small number of participants $(2.3 \%)$ were currently smoking cigarette. Similarly, $9.8 \%$ of participants were currently drink risk alcohol and $1.1 \%$ chew khat. Almost (98.9\%) respondents consuming saturated oil and only $24.8 \%$ of them were consuming vegetables at least five services or slices per day. More than two third (68\%) respondents had low dietary diversity score. Similarly, large proportion of participants $(91.0 \%)$ was engaged in low physical activity(Table 2).

Table2 Magnitude of lifestyle behaviors of middle aged urban residents, west Ethiopia, 2019

\begin{tabular}{llrr} 
Variables & Categories & Frequency & Percentage (\%) \\
\hline Smoking & Current smoker & 6 & 2.3 \\
& Former, but quit now & 21 & 7.9 \\
Alcohol & Never smoker & 239 & 89.8 \\
& Current drunker & 26 & 9.8 \\
\multirow{3}{*}{ Khat } & Former ,but quit now & 40 & 15 \\
& Never & 200 & 75.2 \\
\multirow{4}{*}{ Physical activity } & Current chewer & 3 & 1.1 \\
& Former ,but quit now & 18 & 6.8 \\
& Never & 245 & 92.1 \\
& Physical inactive (Low PA) & 242 & 91.0 \\
& Moderate(3ds\&120-150 m'/wk) & 13 & 4.9 \\
& Vigorous ( $\geq 3$ days/150m'/wk) & 11 & 4.1
\end{tabular}




\begin{tabular}{llrr} 
Sleep & Yes I have apnea & 92 & 34.6 \\
& Sometimes fragmented & 108 & 40.6 \\
& Normal & 66 & 24.8 \\
\hline \multirow{2}{*}{ Salt } & Yes, use $>$ 1teaspoon/>6g/day & 266 & 100 \\
\multirow{2}{*}{ Sugar } & As of standard/ $<6 \mathrm{~g} /$ day & 0 & 0 \\
& Use excess dose & 261 & 98.1 \\
Daily Fruit & As of standard & 5 & 1.9 \\
& > five services/400 g/day/capita & 6 & 2.3 \\
Daily Vegetable & No, but occasionally & 260 & 97.7 \\
\multirow{3}{*}{ Saturated oil } & At least five services/400g/day & 66 & 24.8 \\
& No, but occasionally & 200 & 75.2 \\
dietary diversity score & Saturated oil always & 263 & 98.9 \\
& Clotted oil \& animal butter & 3 & 1.1 \\
& Low dietary diversity & 181 & 68.0 \\
& Medium dietary diversity & 76 & 28.6 \\
& High dietary diversity & 9 & 3.4 \\
\hline
\end{tabular}

\section{Lipid profiles and Anthropometric measurements}

Based on Ethiopian cut points [25] more than half (58.6\%) of the participants were found to have central obesity (WC) and $47.1 \%$ as of IDF [48]. Out of the 266 participants tested, 27.8\%, $16.2 \%, 7.1 \%, 18.4 \%$ and $20.3 \%$ were found to have undiagnosed raised SBP, DBP, FBS ,BP and raised triglycerides respectively(Table 3).

\begin{tabular}{|c|c|c|c|c|}
\hline Variables & Mean \pm SD & Categorical & Frequency & Percent $\%$ \\
\hline \multirow[t]{4}{*}{ BMI $\left(25 \mathrm{~kg} / \mathrm{cm}^{2}\right)$} & $22.85(3.68)$ & Normal & 131 & 49.2 \\
\hline & & Overweight & 52 & 19.5 \\
\hline & & Obese & 65 & 24.4 \\
\hline & & $\begin{array}{l}\text { Chronic energy } \\
\text { deficiency }\end{array}$ & 18 & 6.8 \\
\hline \multirow[t]{2}{*}{ Central obesity } & $85.39(8.37)$ & Yes & 156 & 58.6 \\
\hline & & No & 110 & 41.4 \\
\hline $\mathrm{WC}>90$ for male/ & $85.39(8.37)$ & Yes & 125 & 47.1 \\
\hline \multicolumn{2}{|l|}{$>80 \mathrm{~cm}$ for female } & No & 141 & 52.9 \\
\hline \multirow{2}{*}{$\begin{array}{l}\text { High Hip } \\
\text { circumference }\end{array}$} & $93.49(9.05)$ & Yes & 192 & 72.2 \\
\hline & & No & 74 & 27.8 \\
\hline \multirow{2}{*}{$\begin{array}{l}\text { Raised Systolic } \\
\mathrm{BP} \geq 130\end{array}$} & $120.02(14.24)$ & Yes & 74 & 27.8 \\
\hline & & No & 192 & 72.2 \\
\hline \multirow{2}{*}{$\begin{array}{l}\text { Raised Diastolic } \\
\mathrm{BP} \geq 85\end{array}$} & $77.11(8.98)$ & Yes & 43 & 16.2 \\
\hline & & No & 223 & 83.8 \\
\hline Raised BP & --- & Yes & 49 & 18 \\
\hline
\end{tabular}




\begin{tabular}{|c|c|c|c|c|}
\hline$\geq 130 / 85 \mathrm{mmHg}$ & & No & 217 & 81.6 \\
\hline $\begin{array}{l}\text { Raised } \\
\text { FBS } \geq 100 \mathrm{mg} / \mathrm{dl}\end{array}$ & $99.70(29.60)$ & $\begin{array}{l}\text { Yes } \\
\text { No }\end{array}$ & $\begin{array}{r}19 \\
247\end{array}$ & $\begin{array}{r}7.1 \\
92.9\end{array}$ \\
\hline $\begin{array}{l}\text { Raised TG } \\
\text { level } \geq 150 \mathrm{mg} / \mathrm{dl}\end{array}$ & $131.63(24.92)$ & $\begin{array}{l}\text { Yes } \\
\text { No }\end{array}$ & $\begin{array}{r}54 \\
212\end{array}$ & $\begin{array}{l}20.3 \\
79.7\end{array}$ \\
\hline $\begin{array}{l}\text { Reduced } \mathrm{HDL} \\
<40 \text { for } \mathrm{M} \\
<50 \text { for } \mathrm{F}\end{array}$ & $52.01(10.34)$ & $\begin{array}{l}\text { Yes } \\
\text { No }\end{array}$ & 214 & $\begin{array}{l}19.5 \\
80.5\end{array}$ \\
\hline $\begin{array}{l}\text { Had Metabolic } \\
\text { syndrome }\end{array}$ & -------- & $\begin{array}{l}\text { Yes } \\
\text { No }\end{array}$ & $\begin{array}{r}41 \\
225\end{array}$ & $\begin{array}{l}15.4 \\
84.6\end{array}$ \\
\hline
\end{tabular}

\section{Factors associated with metabolic syndrome}

Findings showed that metabolic syndrome was prevalent and independent factors were significantly associated. On bivariate analysis age, low physical activity, BMI, blood pressure, high fasting, triglyceride, and cholesterol were risk factors for metabolic syndrome. We found metabolic risk would increased by $86 \%$ (OR: 1.82, 95\%CI: 1.82-4.23) for participants aged 4956 years. Regarding triglycerides level the current study demonstrated that those who had risen were found to have high metabolic syndrome than others (OR: 113.18 CI=36.05-355.29). Regarding the topic of BMI, our study revealed those participants who had overweight/obese had 41.37 (OR: 41.37, CI: 11.93, 143.51) times higher chance of having metabolic syndrome than normal range of BMI (Table4).

On multinomial logistic analysis age, BMI, high blood pressure, and HDL-cholesterol showed association for metabolic syndrome, but not significant with diastolic blood pressure $(\mathrm{p}=0.688)$. The developing metabolic risk was about nine times higher in those with systolic blood pressure of $\geq 130 \mathrm{mmHg}$ (AOR: 9.30; 95\% CI 1.12-77.37; P, 0.039). Similarly, FBS $\geq 100 \mathrm{mg} / \mathrm{dl}$ was found to increase metabolic syndrome risk by more than fourfold (AOR: 4.42; 95\% CI 1.91, 10.25; $\mathrm{P}<0.001)$. Finally, high $\mathrm{BMI}$ and age between $49-56$ years were associated with more than twenty five and twelve times developing (AOR: 25.67; 95\% CI 7.18, 94.59; $\mathrm{p}<0.001$ ) and (AOR:12.74; 95\% CI 1.40, 41.49; p, 0.015) respectively (Table 4). 


\begin{tabular}{|c|c|c|c|c|c|c|c|}
\hline \multirow[t]{2}{*}{ Variables } & \multirow[t]{2}{*}{ Categories } & \multicolumn{2}{|c|}{$\begin{array}{l}\text { Metabolic } \\
\text { syndrome }\end{array}$} & \multirow[t]{2}{*}{$\operatorname{cOR}(95 \% \mathrm{CI})$} & \multirow[t]{2}{*}{ p-value } & \multirow[t]{2}{*}{$\mathrm{aOR}(95 \% \mathrm{CI})$} & \multirow[t]{2}{*}{ p-value } \\
\hline & & Yes & No & & & & \\
\hline \multirow[t]{3}{*}{ Age } & $41-48$ years & 22 & 123 & $0.65(0.25,1.53)$ & 0.324 & $0.45(0.02,9.24$ & 0.602 \\
\hline & $49-56$ years & 8 & 69 & $1.86(1.82,4.23)$ & 0.136 & $12.74(1.40,41.49)$ & 0.015 \\
\hline & $57-64$ years & 11 & 33 & 1 & & 1 & \\
\hline \multirow[t]{3}{*}{ Physical activity } & Low & 36 & 206 & $2.54(2.15,8.47)$ & 0.027 & $0.75(0.09,6.44)$ & 0.792 \\
\hline & Vigorous & 3 & 8 & $1.22(1.04,4.89)$ & 0.960 & $7.78(0.37,16.63)$ & 0.190 \\
\hline & Moderate & 2 & 11 & 1 & & 1 & \\
\hline \multirow{3}{*}{$\begin{array}{l}\text { High BMI } \\
(\mathrm{kg} / \mathrm{m} 2\end{array}$} & Normal & 3 & 128 & $5.57(1.43,23.17)$ & 0.018 & $2.01(3.61,11.23)$ & 0.001 \\
\hline & Overweight/Obese & 38 & 79 & $41.37(11.93,143.5$ & $<0.001$ & $25.67(7.18,94.59)$ & $<0.001$ \\
\hline & Chronic energy def & 1 & 17 & 1 & & 1 & \\
\hline \multirow{2}{*}{$\begin{array}{l}\text { High SBP } \\
(\text { yes }>/ \text { no }<\text { ) }\end{array}$} & $>130 \mathrm{mmHg}$ & 22 & 49 & $0.24(0.12,0.48)$ & $<0.001$ & $9.30(1.12,77.37)$ & 0.039 \\
\hline & $<130 \mathrm{mmHg}$ & 19 & 176 & 1 & & 1 & \\
\hline \multirow{2}{*}{$\begin{array}{l}\text { High DBP } \\
(\text { yes }>/ \text { no }<\text { ) }\end{array}$} & $>85 \mathrm{mmHg}$ & 13 & 29 & $0.32(0.15,0.69)$ & 0.003 & $1.54(1.19,12.73)$ & 0.688 \\
\hline & $<85 \mathrm{mmHg}$ & 28 & 196 & 1 & & 1 & \\
\hline \multirow{2}{*}{$\begin{array}{l}\text { High FBS } \\
(\mathrm{mg} / \mathrm{dl})\end{array}$} & $\geq 100$ & 14 & 5 & $0.04(0.02,0.13)$ & $<0.001$ & $4.42(1.91,10.25)$ & 0.001 \\
\hline & $<100$ & 27 & 220 & 1 & & 1 & \\
\hline Raised & $\geq 150 \mathrm{mg} / \mathrm{dl}$ & 37 & 17 & $113.18(36.05,355.29)$ & $<0.001$ & $0.014(0.003,0.063)$ & 0.001 \\
\hline Triglycerides & $<150 \mathrm{mg} / \mathrm{dl}$ & 4 & 208 & 1 & & 1 & \\
\hline \multirow[t]{2}{*}{ HDL-cholesterol } & $\mathrm{Yes}(\mathrm{F}<50 \& \mathrm{M}<40)$ & 22 & 12 & $22.30(9.98,49.82)$ & $<0.001$ & $0.05(0.01,0.13)$ & 0.001 \\
\hline & No & 29 & 203 & 1 & & 1 & \\
\hline
\end{tabular}

\section{DISCUSSION}

The study reveals unscreened metabolic syndrome and its associated factors among urban residents of west Ethiopia. It demonstrated that high ORs of metabolic syndrome increased with its component factors; both ORs \& AOR increased with presence of mobility problem.

The magnitude of metabolic syndrome was $12.6 \%$ IDF [48] and15.4\% according to [25]; its component like raised triglyceride, hypertension, and raised fasting blood sugar were 20.3, 18.4 and $7.1 \%$ respectively. From the participants had metabolic syndrome, $67.69 \%$ of them were females and of those had poorer, adults' aged $41-48$ years accounts $50.77 \%$.

Inline to our study, other studies result demonstrated that the prevalence was significantly higher in the middle aged, and sky rocket in middle age [9, 30-31] and typically declines in the elderly [32]. The magnitude of metabolic syndrome in the present study was less than previously documented findings from some urban areas of Ethiopia like Addis Ababa (17.9\%) [49].

The prevalence of undiagnosed $\mathrm{FBS} \geq 100 \mathrm{mg} / \mathrm{dl}$ (7.1\%) was less comparatively with pooled results of urban areas of Sudan (7.7\%)[42], urban Egypt (20\%)[9] and red delta river of middleaged Vietnam (40\%)[33]. Study conducted in north Indian, prevalence of metabolic syndrome was $32.5 \%$ which is higher than this finding [46]. 
Worldwide, one in four (23\%) of adults do not currently meet the global recommendations for physical activity [16] which was less compared to this study (91.0\%). This result was highly prevalent. We found physical inactivity was associated with metabolic syndrome, this confirms the study done in other country $[34,35]$.

Waist circumference is a measure of central obesity as per IDF as well as ATP-III criteria was $48.1 \%$. But based on the cut off points [24], this study reveals $58.6 \%$ of adults have high waist circumference which have nearly similar result with study conducted on Jimma University workers $(58.9 \%)[22,24]$. The mean $\pm \mathrm{SD}$ of central obesity $(85.39 \pm 8.37)$ of our study result was higher than this cut of point but lower than German firefighters (89.9 10.0$)$ and office workers $(97.3 \pm 11.7)[41]$.

Similar to this finding, degenerative like: hypertension [44], diabetes [45] and coronary heart disease [47] associated significant and also in Iran. This study adds message for public health to stress on community based diagnosis of NCD, dose of sodium diet intake, fruit and vegetable consumption and others food groups by community. Approximately, all participants consume greater than a teaspoon ( $>6 \mathrm{~g} /$ day) of salt a day, $58.6 \%$ of them had central obesity and $18.4 \%$ elevated blood pressure. These findings confirm with other studies, elevated blood pressure [3637] and central area obesity [38-39] related to high-sodium diet. Also majority (97.7 and 75.2\%) of the respondents occasionally or not at all consume fruit and vegetables respectively. Dietary guidelines also consider ethnic backgrounds, since Ethiopian did not have dietary guidelines, so it needs other formulation to define their association.

\section{CONCLUSIONS}

The magnitude of metabolic syndrome in urban residents of west Ethiopia was 15.4\% while $12.6 \%$ based on new clinical IDF [48]. Association found between the variables. Therefore, to reduce the magnitude, curb burden of NCD and improve health adults, it is recommended: applying holistic lifestyle intervention approach, launching health and nutrition information system or community-based service delivery system and active screening for early detection of risk factors would bring significant changes. To sum up, establishing healthy lifestyles training, diet therapy and NCD prevention center is crucial for awareness creation, capacity building, rehabilitation and job creation at all.

\section{Limitations of the Study}


The study is subject to recall bias because of the cress sectional nature and unhealthy lifestyles practices were hidden by respondents due to socially unacceptable behaviors which might under or overestimate the actual levels of risk factors. Any other bottle neck was insufficient biochemical reagent to take large study population.

\section{Ethical approval}

This study was approved by the Institutional Review Board of Jimma University (Approval No. IHRPGD/596/2019; January 1, 2019). Support letter was also taken from all concerned bodies. Prior to the first interview, participants were informed about objectives of the study and privacy during the interview. Written consent was also obtained from individual participants.

\section{Consent for Publication}

Not applicable

\section{Disclosure}

$>$ We declare that there is no competing interest.

\section{Funding}

The authors were not received financial support for the publication, but fund for facilitating data collection allocated by Jimma University.

\section{Author Contributions}

All made substantial to conception from proposal construction, data collection and manuscript writing to final approval of the version to be published.

\section{Acknowledgements}

We acknowledge all participants, professionals, Nekemte Health Bureau, Wollega University specialized hospital, cheleleki clinic, staffs and health extension workers.

\section{REFERENCES}

1. Sommer I, Griebler U, Mahlknecht P, Thaler K, Bouskill K, Gartlehner G, Mendis S. Socioeconomic inequalities in non-communicable diseases and their risk factors: an 
overview of systematic reviews. BMC Public Health. 2015;15:914.View ArticlePubMedPubMed CentralGoogle Scholar.

2. S. Friel, M. Chopra and D. Satcher, "Unequal Weight: Equity Oriented Responses to the Global Obesity Epidemic" British Medical Journal 335 (2007):1241; B. Popkin, “Does Global Obesity Represent a Global Public Health Challenge?” American Journal of Clinical Nutrition 93(2) (2011): 232-3.

3. World Health Organization, 2002. Diet, physical activity and health. Geneva, (documents A55/16 and A55/16 Corr.1).

4. Abdulkadir J, Ahmed R (2001) Management of diabetes mellitus: coping with limited facilities. Ethiopian Medical Journal 39: 349-365.

5. Mistire Wolde Gebre, 2013. Diabetes mellitus and associated diseases from Ethiopian perspective: Systematic review. Ethiop. J. Health Dev. 2013; 27(3):249-253.

6. Wakjira ZN, Berha AB (2017) Screening Employees for Undiagnosed Type 2 Diabetes Mellitus and Evaluation of Risk Scores in Tikur Anbessa Specialized Hospital, Addis Ababa, Ethiopia. J Diabetes Metab 8: 765. doi:10.4172/2155-6156.1000765.

7. Yan Zhang1, Defu Ma2, Renzhe Cui3, Esayas Haregot Hilawe1, Chifa Chiang1, Yoshihisa Hirakawa1, Yonghua Hu2, Peiyu Wang2, Hiroyasu Iso3 and Atsuko Aoyama1. Facilitators and barriers of adopting healthy lifestyle in rural China: a qualitative analysis through social capital perspectives. Nagoya J. Med. Sci. 78. 163 $173,2016$.

8. Grundy SM, Cleeman JI, Daniels SR, et al. Diagnosis and management of the metabolic syndrome: an American Heart Association/National Heart, Lung, and Blood Institute Scientific Statement. Circulation 2005;112:2735-52.

9. WHO. Obesity and overweight. WHO 2015, Fact sheet $\mathrm{N}^{\circ} 311$. http://www.who.int/mediacentre/ factsheets/fs311/en/. Accessed February 23, 2015.

10. Kaur J. A comprehensive review on metabolic syndrome. Cardiol Res Pract. 2014;2014:943162. doi:10.1155/2014/943162.

11. Spark, Arlene J. Nutrition in public health : principles, policies, and practice / author, Arlene Spark. p. ; cm. ISBN-13: 978 0-8493-1473-5 (hardcover : alk. paper) ISBN-10: 08493-1473-9 (hardcover : alk. paper). Hunter University, NewYork ,U.S.A. 2007 by Taylor \& Francis Group, LLC. 
12. Kularatna S, Whitty JA, Johnson NW, Jayasinghe R, Scuffham PA (2014) EQ-5D-3L Derived Population Norms for Health Related Quality of Life in Sri Lanka. PLoS ONE 9(11): e108434. doi:10.1371/journal.pone.0108434.

13. Dietz, W.H., R.C. Brownson, C.E. Douglas, J.J. Dreyzehner, R.Z. Goetzel, S.L. Gortmaker, J.S. Marks, K.A. Merrigan, R.R. Pate, L.M. Powell, and M. Story. 2016. Improving Physical Activity and Nutrition and Reducing Tobacco Use and Obesity to Prevent Chronic Disease. Discussion Paper, Vital Directions for Health and Health Care Series. National Academy of Medicine, Washington, DC. https://nam.edu/wp-content/uploads/2016/09/chronic-disease-prevention-tobacco-physical-activity-and-nutrition-for-ahealthy-start.pdf

14. Medical diseases dictionary, 2017.

15. Hawkes C. 2013. Promoting healthy diets through nutrition education and changes in the food environment: an international review of actions and their effectiveness. Rome: Nutrition Education and Consumer Awareness Group, FAO of the United Nations. Available at www.fao.org/ag/humannutrition/nutritioneducation/69725/en/.

16. WHO (2016j). World Health Organization.

17. Nelia P. Steyn and Zandile J. Mchiza. Obesity and the nutrition transition in Sub-Saharan Africa. Article in Annals of the New York Academy of Sciences · April 2014 DOI: $10.1111 /$ nyas. 12433

18. Mattie, J., V. Malik, N.M. Wedick, et al. 2012. A symposium and workshop report from the Global Nutrition and Epidemiologic Transition Initiative: nutrition transition and the global burden of type 2 diabetes. Br. J. Nutr. 10 8: 1325-1335.

19. Vogl M, Wenig CM, Leidl R, Pokhrel S. Smoking and health-related quality of life in English general population: implications for economic evaluations. BMC Public Health 2012;12:203.

20. Abda E, Hamza L, Tessema F, Cheneke W. Metabolic syndrome and associated factors among outpatients of Jimma University Teaching hospital. Diabetes, metabolic syndrome and obesity: targets and therapy. 2016; 9:47. https://doi.org/10.2147/DMSO.S97561 PMID: 27019600.

21. Misra A, Khurana L. Obesity and the metabolic syndrome in developing countries. J Clin Endocrinol Metab.2008;93(11_supplement_1): S9-S30. doi:10.1210/jc.2008-1595 
22. Peer N, Steyn K, Lombard C, et al. A high burden of hypertension in the urban black population of Cape Town: the cardiovascular Risk in Black South Africans (CRISBA) study. PLoS One. 2013;8(11):11. doi:10.1371/journal.pone.0078567

23. Girum Tefera, 2015. Determinants of Proteinuria among Type 2 Diabetic Patients at Shakiso Health Center, Southern Ethiopia: A Retrospective Study. Advances in Diabetes and $\quad$ Metabolism 2(3): 48-54, $2014 \quad$ http://www.hrpub.org. DOI:10.13189/adm.2014.020302.

24. Rajesh.P.N1*, Andualem Mossie2, Yinebeb Mezgebu. Prevalence Of Metabolic Syndrome And Its Components In Jimma Town, South West Ethiopia.;Vol. 3|Issue 03|Pg:1685-1704. 2016; DOI: 10.18535/ijmsci/v3i3.7

25. Makeda Sinaga1, Meron Worku, Tilahun Yemane, Elsah Tegene, Tolassa Wakayo1, Tsinuel Girma, David Lindstrom and Tefera Belachew1 (2018). Optimal cut-off for obesity and markers of metabolic syndrome for Ethiopian adults. Nutrition Journal201817:109 https://doi.org/10.1186/s12937-018-0416-0.

26. Wildman RP, Muntner P, Reynolds K, et al. The obese without cardio-metabolic risk factor clustering and the normal weight with cardio-metabolic risk factor clustering: prevalence and correlates of 2 phenotypes among the US population (NHANES 1999-2004). Arch Intern Med. 2008; 168:1617e1624.

27. Meigs JB, Wilson PW, Fox CS, et al. Body mass index, metabolic syndrome, and risk of type 2 diabetes or cardiovascular disease. J Clin Endocrinol Metab. 2006; 91:2906e2912.

28. Central statistic Agency,2007. Nekemte city.

29. William.T. Freidwald et al. Estimation of the concentration of LDL-C in plasma without the use of preparative ultracentrifuge. Clinical chemistry1972;18: No.6.

30. Cogill B: Anthropometric Indicators Measurement Guide. In.: Food and Nutrition Technical Assisitance 2003.

31. Finucane MM, Stevens GA, Cowan MJ, Danaei G, Lin JK, Paciorek CJ, et al. National, regional, and global trends in body-mass index since 1980: systematic analysis of health examination surveys and epidemiological studies with 960 country-years and 9.1 million participants. Lancet. 2011; 377:557-567. [PubMed: 21295846].

32. World Health Organization (WHO,2011): Obesity. Preventing and Managing the Global epidemic. Report of WHO consultation on Obesity 3-5th June 1997, WHO Geneva. 2011 [http://whqlibdoc.who.int/hq/1998/ WHO_NUT_NCD_98.1_(p1-158).pdf], Accessed on 27th April. 
33. Holl RW, Hoffmeister U, Thamm M et al. Does obesity lead to a specific lipid disorder? Analysis from the German/Austrian/Swiss APV registry. Int J Pediatr Obes. 2011; 6 Suppl 1: 53-8.

34. Binh TQ, Phuong PT, Nhung BT, et al. Metabolic syndrome among a middle-aged population in the Red River Delta region of Vietnam. BMC Endocr Disord 2014;14:77.

35. Lakka TA, Laaksonen DE, Lakka HM et al. Sedentary lifestyle, poor cardiorespiratory fitness, and the metabolic syndrome. Med Sci Sports Exerc 2003;35:1279-86.

36. Goudarzi R, Zeraati H, Akbari Sari A, Rashidian A, Mohammad K. Population-based preference weights for the EQ-5D health states using the visual analogue scale (VAS) in Iran. Iran Red Crescent Med J 2016;18:e21584.

37. Sacks FM, Svetkey LP, Vollmer WM et al. Effects on blood pressure of reduced dietary sodium and the Dietary Approaches to Stop Hypertension (DASH) diet. DASH-Sodium Collaborative Research Group. N Engl J Med 2001;344:3-10.

38. Geleijnse JM, Kok FJ, Grobbee DE. Blood pressure response to changes in sodium and potassium intake: a metaregression analysis of randomised trials. J Hum Hypertens 2003;17:471-80.

39. Baudrand R, Campino C, Carvajal CA et al. High sodium intake is associated with increased glucocorticoid production, insulin resistance and metabolic syndrome. Clin Endocrinol (Oxf) 2014;80:677-84.

40. Zhou X, Yuan F, Ji WJ et al. High-salt intake induced visceral adipose tissue hypoxia and its association with circulating monocyte subsets in humans. Obesity (Silver Spring) 2014.

41. Tran A, GelayeB, GirmaB, et al. Prevalence of Metabolic Syndrome among Working Adults in Ethiopia. International J. Hypertension, 2011; 193719.

42. Markus Strauß1*, Peter Foshag1, Bianca Przybylek1, Marc Horlitz2, Alejandro Lucia3,4, Fabian Sanchis-Gomar3 and Roman Leischik1. Occupation and metabolic syndrome: is there correlation? A cross sectional study in different work activity occupations of German firefighters and office workers. Strauß et al. Diabetol Metab Syndr (2016) 8:57 DOI 10.1186/s13098-016-0174-0.

43. World Health Organization (WHO, EMR 2011). Prevalence of diabetes in World.

44. Karyani AK, Rashidian A, Sefiddashti SE, Sari AA. Self-reported health-related quality of life (HRQoL) and factors affecting HRQoL among individuals with health insurance in Iran. Epidemiol Health 2016; 38:e2016046. 
45. Kitaoka M, Mitoma J, Asakura H, Anyenda OE, Nguyen TT, Hamagishi T, et al. The relationship between hypertension and healthrelated quality of life: adjusted by chronic pain, chronic diseases, and life habits in the general middle-aged population in Japan. Environ Health Prev Med 2016;21:193-214.

46. Hajian-Tilaki K, Heidari B, Hajian-Tilaki A. Solitary and combined negative influences of diabetes, obesity and hypertension on health-related quality of life of elderly individuals: a population-based cross-sectional study. Diabetes Metab Syndr 2016;10: S37-S42.

47. Rambha Pathak, Rashmi Agarwalla, Deepak Pathania. "Assessment of metabolic syndrome and health related quality of life in community dwellers: A cross sectional study from North India", Indian Journal of Medical Specialities, 2018.

48. International Diabetes Federation. The IDF consensus worldwide definition of the metabolic syndrome. 2018. cited 14th January 2017, Available from: http://www.idf.org/webdata/docs/MetS def update2006.pdf.

49. Gebreyes YF, Goshu DY, Geletew TK, et al. Prevalence of high blood pressure, hyperglycemia, dyslipidemia, metabolic syndrome and their determinants in Ethiopia: evidences from the National NCDs STEPS. PLoS One. 2018;13(5):1-18. doi:10.1371/journal. pone.0194819 